\title{
Impactos ambientais e toxicológicos da lixiviação em tijolos cerâmicos com adição de resíduos: uma revisão bibliográfica
}

\author{
Serafini, Ramoel ${ }^{1}$; Carvalho, João Paulo Barbosa ${ }^{2}$; de Figueiredo, Antonio \\ Domingues $^{3}$ \\ ${ }^{1}$ Mestrando, Universidade de São Paulo, rserafini@usp.br \\ ${ }^{2}$ Mestrando, Universidade de São Paulo, joaopaulobc01@usp.br \\ ${ }^{3}$ Professor, Universidade de São Paulo, antonio.figueiredo@usp.br
}

\begin{abstract}
Resumo: A adequada destinação de resíduos é um dos tópicos prioritários no que tange a sustentabilidade ambiental. Uma das práticas que vêm sendo adotada é a de incorporação destes resíduos em tijolos cerâmicos. Estes materiais estão sujeitos à ação de mecanismos deletérios, como a lixiviação que possui a capacidade de carrear elementos químicos. Este processo pode vir a gerar riscos à saúde humana e ao meio ambiente. Nesse contexto, o presente trabalho propõe avaliar a influência do teor de incorporação e a temperatura de queima nas concentrações de elementos perigosos na solução lixiviada de tijolos. A metodologia adotada consistiu da catalogação de trabalhos científicos publicados encontrados em bases de dados entre os anos de 2012 e 2017 e posterior análise dos resultados quanto à conformidade com as normas adotadas. De forma adicional, as propriedades de porosidade, absorção de água e resistência mecânica à flexão foram correlacionadas em função da temperatura de queima e do teor de resíduo incorporado. Os resultados demonstram que os tijolos com incorporação de resíduos são capazes de manter dentro dos parâmetros normativos os teores materiais perigosos ou tóxicos da solução lixiviante. Além disso, os resultados demonstram que há influência tanto do teor de incorporação de resíduo quanto da temperatura de queima nas propriedades dos tijolos com incorporação de resíduos.
\end{abstract}

Palavras-chave: tijolos cerâmicos, resíduos, lixiviação, deterioração.

Abstract: The adequate waste disposal is one of the priority topics in environmental sustainability. One of the practices that have been adopted is the incorporation of these residues in ceramic bricks. These materials are subject to the action of deleterious mechanisms, such as leaching that has the ability to carry chemical elements. This process can generate risks to human health and the environment. In this context, the present work has the proposal to evaluate the influence of the incorporation content and the firing temperature in the concentrations of dangerous elements in the leached solution of bricks with incorporation of residues. The methodology adopted consisted of the cataloging of published scientific papers found in databases between the years of 2012 and 2017 and subsequent analysis of the results regarding compliance with the adopted standards. Additionally, the properties of porosity, water absorption and flexural strength were correlated with the firing temperature and the incorporated residue content. The results demonstrate that bricks incorporating residues are capable of maintaining within the normative parameters concerning hazardous or toxic material contents of the leaching solution. The results also show that there is influence both the content of incorporation of the residue and the temperature of firing in the properties of the bricks with incorporation of residues.

Keywords: ceramic bricks, residues, leaching, deterioration. 
SERAFINI, R.; CARVALHO, J.P.B.; DE FIGUEIREDO, A.D., IMPACTOS AMBIENTAIS E TOXICOLÓGICOS DA LIXIVIAÇÃO EM TIJOLOS CERÂMICOS COM ADIÇÃO DE RESÍDUOS: UMA REVISÃO BIBLIOGRÁFICA. $3^{\circ}$ Simpósio Paranaense de Patologia das Construções (30 SPPC), artigo 3SPPC1006, pp. 60 - 71, 2018. DOI: 10.4322/2526-7248.006

\section{Introdução}

Os processos industriais, da agricultura e também do meio urbano produzem grandes quantidades de resíduos, estes por sua vez, podem ser incluídos na cadeia produtiva de tijolos cerâmicos para a construção civil, visto que, além de dar destino para estes subprodutos, sua inclusão pode minimizar o uso de produtos virgens e, dependendo do resíduo, melhorar algumas propriedades de tijolos à base de argila. Além disso, sua incorporação é capaz de estabilizar e solidificar elementos perigosos, visto que essa é capaz de diminuir a mobilidade de metais através da imobilização físico-química; melhorar as características físicas por meio da solidificação do resíduo e reduzir a superfície de constituintes de resíduo exposta ao processo de lixiviação.

Pode-se notar que, embora haja vantagens na utilização de resíduos em tijolos cerâmicos, alguns cuidados devem ser tomados, principalmente no que tange a sua exposição à mecanismos de degradação. Através dos estudos de degradação, especialistas podem deliberar, com maior embasamento, acerca dos modos de intervenção e o grau de deterioração de um elemento construtivo [1]. Isto se dá em virtude da solução lixiviante de tijolos com rejeito ter a capacidade de: (i) carrear elementos perigosos e/ou tóxicos que podem atingir lençóis freáticos, causando danos ambientais; (ii) de gerar riscos à saúde dos usuários da edificação; (iii) e colocar em risco as pessoas que trabalham diretamente com esses materiais [2].

É possível verificar, então, a necessidade do estudo individualizado dos processos de degradação de tijolos cerâmicos com incorporação de resíduos. Sendo assim, o presente estudo tem o objetivo de, por meio de uma revisão bibliográfica, avaliar a capacidade de solidificação/estabilização de elementos perigosos presentes em resíduos em tijolos cerâmicos. De forma adicional, foram avaliados os impactos da incorporação de resíduo nas propriedades de porosidade, absorção de água e resistência à flexão. Por fim, buscou-se verificar se há alguma relação entre a concentração de elementos lixiviados com o teor de incorporação do resíduo para os elementos com maior espaço amostral nesta pesquisa.

\section{Fundamentação}

\subsection{Estabilização e solidificação de materiais perigosos}

O processo de Solidificação/Estabilização (S/E) de materiais perigosos é um processo que restringe a migração de contaminantes para receptores humanos, animais ou vegetais - agindo como modo de proteção do meio ambiente e da saúde humana [3]. O princípio básico deste processo envolve a mistura de um reagente aglomerante com o material em questão. A solidificação se refere às mudanças nas propriedades físicas de um resíduo - como aumento da resistência à compressão, redução de permeabilidade e encapsulamento de constituintes perigosos. Já a estabilização trata das alterações químicas dos constituintes perigosos de um resíduo - como reduzir a solubilidade, mobilidade ou forma tóxica do material [4].

\subsection{Lixiviação}

Lixiviação é o processo deletério de extração dos constituintes químicos de um material através de um meio líquido. Esse evento pode vir a ocorrer em situações 
SERAFINI, R.; CARVALHO, J.P.B.; DE FIGUEIREDO, A.D., IMPACTOS AMBIENTAIS E TOXICOLÓGICOS DA LIXIVIAÇÃO EM TIJOLOS CERÂMICOS COM ADIÇÃO DE RESÍDUOS: UMA REVISÃO BIBLIOGRÁFICA. $3^{\circ}$ Simpósio Paranaense de Patologia das Construções (30 SPPC), artigo 3SPPC1006, pp. 60 - 71, 2018. DOI: 10.4322/2526-7248.006

naturais, através de infiltrações, pela influência da precipitação, ou através de simulações em laboratório. Como um todo, a lixiviação pode ser explicada através de três pilares principais: mecanismo, método, e fatores contribuintes. O mecanismo de lixiviação é responsável por explicar o modo como ocorre a lixiviação de um material; o método de lixiviação corresponde aos tipos de lixiviação existentes; e, por fim, os fatores que afetam a lixiviação são variáveis que influenciam no processo deletério.

\subsubsection{Mecanismo de Lixiviação}

O processo de lixiviação tem início através da solubilização, geralmente proveniente de reações químicas, de partículas de um sólido que reagem com a água presente dentro dos poros do material ou com a solução lixiviante que permeia o sólido $[5,6]$. Entretanto, após a dissolução inicial a taxa de lixiviação é regulada por difusão - o que faz com que os mecanismos de lixiviação nem sempre sejam tão simplificados [7].

Nesse contexto os testes de lixiviação baseados em difusão podem ser realizados através de dois modelos principais de interação com o material sendo eles por lavagem superficial e flow-through. A principal diferença é que a lavagem superficial ocorre quando a solução lixiviante passa ao redor do resíduo, havendo uma interação com ausência de pressão, ou seja, o processo é realizado em todas as direções. Já a interação por flow-through ocorre quando há pressão e a solução lixiviante é forçada a entrar em contato com o resíduo, resultando em um fluxo direcional de transporte dos componentes lixiviados [8].

A lixiviação por lavagem superficial é utilizada em situações que o resíduo é menos permeável que o material no seu entorno. Nesta situação, o interior dos poros encontra-se saturado com lixiviante e a difusão ocorre na interface sólido-liquido dentro dos poros [6].

Para situações regulares de exposição à chuva na construção civil o mecanismo de difusão ocorre de maneira similar, no entanto devem ser adicionados ao fator tempo os fatores de ciclos de molhagem e secagem na camada externa, e difusão para maiores profundidades [9]. Sendo assim, ensaios de corpos-de-prova submersos em soluções lixiviantes podem não reproduzir, de forma adequada, resultados reais.

\subsubsection{Métodos de ensaio}

Os ensaios de lixiviação podem ser classificados em estáticos e dinâmicos [10]. Os ensaios estáticos têm como característica a ausência de renovação da solução lixiviante e podem ser por agitação - como descrito na norma Toxicity Characteristics Leaching Procedures (TCLP) da United States Environmental Protection Agency [11]; e a norma NBR 10.005 da Associação Brasileira de Normas Técnicas [12]. Já em métodos de ensaio dinâmicos a solução lixiviante é renovada e os resíduos estabilizados ou solidificados são expostos aos mecanismos de difusão ou de percolação - nos quais o tempo é um fator de elevada importância [13]. Dessa forma, diferentes ensaios podem ser aplicados como a norma ANS 16.1 [14], NEN 7345 [15], NFX 31-210 [16]. 
SERAFINI, R.; CARVALHO, J.P.B.; DE FIGUEIREDO, A.D., IMPACTOS AMBIENTAIS E TOXICOLÓGICOS DA LIXIVIAÇÃO EM TIJOLOS CERÂMICOS COM ADIÇÃO DE RESÍDUOS: UMA REVISÃO BIBLIOGRÁFICA. $3^{\circ}$ Simpósio Paranaense de Patologia das Construções (30 SPPC), artigo 3SPPC1006, pp. 60 - 71, 2018. DOI: 10.4322/2526-7248.006

\subsubsection{Fatores que influenciam na lixiviação}

As características físicas e a composição química do material avaliado podem afetar direta e indiretamente o processo de liberação de resíduos estabilizados, solidificados ou granulares. Entre os fatores físicos, os mais relevantes estão ligados à área superficial, o escoamento pela partícula, a técnica de agitação e equipamento utilizados, as características da solução lixiviante, a proporção solução lixiviante/ amostra, o tempo de contato, e a temperatura (Tabela 1).

Tabela 1: Alguns aspectos físicos e sua influência no processo lixiviante

\begin{tabular}{cl}
\hline Aspecto físico & \multicolumn{3}{c}{ Influência na lixiviação } \\
\hline Área superficial do sólido & $\begin{array}{l}\text { A redução da granulometria aumenta a área superficial, } \\
\text { aumentando a lixiviação }\end{array}$ \\
\hline Porosidade & $\begin{array}{l}\text { A baixa porosidade reduz a permeabilidade, reduzindo a } \\
\text { velocidade do fluxo da lixiviação }\end{array}$ \\
\hline $\begin{array}{c}\text { Característica da solução } \\
\text { lixiviante }\end{array}$ & $\begin{array}{l}\text { Soluções lixiviantes com pH ácido aumentam a solubilidade de } \\
\text { fases minerais contidas em resíduos potencialmente } \\
\text { perigosos, aumentando a lixiviação }\end{array}$ \\
\hline $\begin{array}{c}\text { Proporção solução } \\
\text { lixiviante/amostra }\end{array}$ & $\begin{array}{l}\text { Baixa proporção solução lixiviante/amostra reduz a } \\
\text { solubilidade de certos constituintes. }\end{array}$ \\
\hline Tempo & $\begin{array}{l}\text { Quanto menor o tempo de contato entre a solução lixiviante e } \\
\text { o sólido, menor a probabilidade de alcançar ou aproximar-se } \\
\text { do equilíbrio entre sólido e líquido. }\end{array}$ \\
\hline Temperatura & $\begin{array}{l}\text { A solubilidade de certos constituintes é função da temperatura. } \\
\text { De forma geral, elevadas temperaturas favorecem a } \\
\text { solubilidade dos sais. }\end{array}$ \\
\hline
\end{tabular}

Fonte: [17]

Já entre os fatores químicos mais relevantes pode-se citar a influência do $\mathrm{pH}$, reações de hidrólise, potencial redox, e a dissolução por ácidos ou por fundentes orgânicos (Tabela 2).

Tabela 2: Alguns aspectos químicos e sua influência no processo lixiviante

\begin{tabular}{cl}
\hline Aspecto químico & \multicolumn{1}{c}{ Influência na lixiviação } \\
\hline $\begin{array}{c}\text { Potencial } \\
\text { Hidrogeniônico }(\mathrm{pH})\end{array}$ & $\begin{array}{l}\text { Está entre os fatores químicos que mais interferem na lixiviação, além de } \\
\text { controlar demais fatores químicos. Gera lixiviabilidade de constituintes de } \\
\text { resíduos sólidos. }\end{array}$ \\
\hline Hidrólise & $\begin{array}{l}\text { Processo em que um metal reage com água formando um novo } \\
\text { composto metálico iônico ou neutro que apresenta diferente solubilidade } \\
\text { entre si. Por sua vez a solubilização do novo composto está associada à } \\
\text { sua própria natureza e a natureza da solução lixiviante empregada, } \\
\text { assim como outras variáveis. }\end{array}$ \\
\hline Potencial Redox & $\begin{array}{l}\text { Influi na mobilidade de alguns metais através de uma matriz sólida } \\
\text { quando há presença de agentes oxidantes e redutores. Em condições } \\
\text { redutoras, normalmente a lixiviação de metais diminui. }\end{array}$ \\
\hline Fundentes ón ácidos & $\begin{array}{l}\text { Ácido clorídrico, água régia (ácido clorídrico e ácido nítrico), por exemplo, } \\
\text { tem a capacidade de solubilizar materiais. }\end{array}$ \\
\hline & $\begin{array}{l}\text { Substâncias que não são dissolvidas por ácidos geralmente podem ser } \\
\text { dissolvidas por um fundente orgânico fundido, como por exemplo } \\
\text { pirosulfato de potássio, peróxido de sódio e hidróxido de sódio, carbonato } \\
\text { de sódio, entre outros. }\end{array}$ \\
\hline
\end{tabular}

Fonte: [3] [18] [19] 
SERAFINI, R.; CARVALHO, J.P.B.; DE FIGUEIREDO, A.D., IMPACTOS AMBIENTAIS E TOXICOLÓGICOS DA LIXIVIAÇÃO EM TIJOLOS CERÂMICOS COM ADIÇÃO DE RESÍDUOS: UMA REVISÃO BIBLIOGRÁFICA. $3^{\circ}$ Simpósio Paranaense de Patologia das Construções (30 SPPC), artigo 3SPPC1006, pp. 60 - 71, 2018. DOI: 10.4322/2526-7248.006

\section{Metodologia da pesquisa}

Este estudo é composto por uma revisão da literatura especializada publicada entre janeiro de 2012 e abril de 2017 - excluindo-se artigos de revisão, patente e capítulos de livros - tratando de temas relacionados a avaliação dos elementos transportados por lixiviação em tijolos cerâmicos e seus impactos técnicos, sociais e ambientais. Para isso, realizou-se consulta a artigos científicos presentes no banco de dados Scielo e Elsevier ScienceDirect, buscando, em português e inglês, pelas seguintes palavras-chave: tijolos cerâmicos (clay bricks), lixiviação (leaching), perigosos (hazordous), tóxicos (toxic), metais pesados (heavy metals).

Os critérios de inclusão utilizados por esta revisão foram: a presença de ensaios de lixiviação ou solubilização em tijolos cerâmicos; e a caracterização e avaliação do material lixiviado quanto ao seu impacto social ou ambiental em comparação às normativas nacionais e internacionais. Após coleta dos estudos, buscou-se avaliar os resultados obtidos pelos diversos teores de incorporação de resíduo, destacando-se os limites de incorporação encontrados por cada autor; a influência da temperatura de queima e do teor de resíduo nas propriedades dos tijolos; e a capacidade de tijolos cerâmicos de estabilizar dos materiais perigosos e tóxicos.

A análise foi realizada através da coleta dos dados levantados na bibliografia encontrada. Os dados que não fornecidos pela bibliografia e apenas apresentados em gráficos foram estimados por aproximação linear. As informações foram, então, colocadas em tabelas e separadas por variável. Através desta organização e da análise dos artigos foi possível identificar quais os percentuais críticos e a adequação de cada teor de incorporação de resíduo nas propriedades do material lixiviado. Em virtude dos estudos trabalharem com diferentes unidades de medida de acordo com a norma utilizada, apenas os com medições em mg.m-2 foram utilizados, visto que dispunham do maior espaço amostral disponível com mesma terminologia. De forma adicional, os gráficos e linhas de tendência também foram gerados para as variáveis de porosidade, absorção de água e resistência à flexão em função da temperatura de queima e do percentual de incorporação de resíduo, desta vez utilizando todos os trabalhos que dispunham de tais informações.

\section{Análise dos resultados}

Através da pesquisa nas bases de dados consultadas foram encontrados 7 artigos que versavam sobre os impactos da incorporação de resíduos em blocos cerâmicos afetados pelo processo de lixiviação - segundo os critérios de inclusão.

Tratam-se de estudos que visam quantificar e analisar elementos perigosos transportados por processos lixiviantes em blocos e tijolos cerâmicos utilizados na construção civil. Um resumo prático dos trabalhos é previamente apresentado na Tabela 4, com informações quanto ao tipo de resíduo, temperatura de queima e a norma utilizada para o ensaio de lixiviação.

Utilizando-se dos ensaios realizados nos artigos encontrados, buscou-se identificar as relações entre as variáveis avaliadas e a temperatura de cozimento dos tijolos e o percentual de resíduo substituído nos tijolos. Esta análise foi feita baseando-se nos dados dos artigos que possuíam tais informações [20, 23-27], independentemente do tipo de resíduo utilizado. Vale ressaltar que não houve 
SERAFINI, R.; CARVALHO, J.P.B.; DE FIGUEIREDO, A.D., IMPACTOS AMBIENTAIS E TOXICOLÓGICOS DA LIXIVIAÇÃO EM TIJOLOS CERÂMICOS COM ADIÇÃO DE RESÍDUOS: UMA REVISÃO BIBLIOGRÁFICA. $3^{\circ}$ Simpósio Paranaense de Patologia das Construções (30 SPPC), artigo 3SPPC1006, pp. 60 - 71, 2018. DOI: 10.4322/2526-7248.006

quantidade significativa de dados referentes resistência à compressão simples, 0 que levou os autores a optar pela exclusão desta variável. Dessa forma, foram gerados os gráficos, apresentados na Figura 1, que correlacionam as propriedades avaliadas com temperatura de cozimento e percentual de substituição.

Tabela 3: Artigos avaliados nesta revisão bibliográfica

\begin{tabular}{|c|c|c|c|c|}
\hline Autores & Tipo de resíduo & Propriedades avaliadas & Local & Ano \\
\hline [20] & $\begin{array}{l}\text { Lodo Férrico e areia de } \\
\text { fundição }\end{array}$ & $\begin{array}{l}\text { Lixiviação, resistência à flexão, } \\
\text { absorção de água, densidade, } \\
\text { porosidade aberta; e emissão de gases } \\
\text { durante a queima }\end{array}$ & Espanha & 2012 \\
\hline [21] & $\begin{array}{l}\text { Lodo físico-químico, } \\
\text { biológico, de papel e } \\
\text { resíduo florestal }\end{array}$ & $\begin{array}{c}\text { Lixiviação e toxicidade para os seres } \\
\text { humanos }\end{array}$ & Espanha & 2012 \\
\hline [22] & $\begin{array}{l}\text { Lodo da indústria } \\
\text { automotiva (1\%-40\%) }\end{array}$ & Lixiviação e encapsulamento de metais & Colombia & 2013 \\
\hline [23] & $\begin{array}{l}\text { Resíduo da incineração } \\
\text { de resíduos sólidos } \\
\text { municipais (1\%-40\%) }\end{array}$ & $\begin{array}{l}\text { Lixiviação, resistência à compressão, } \\
\text { absorção de água, }\end{array}$ & Colombia & 2013 \\
\hline [24] & Lodo Biológico (15\%) & $\begin{array}{l}\text { Lixiviação, absorção de água, e } \\
\text { resistência à compressão }\end{array}$ & Colombia & 2015 \\
\hline [25] & $\begin{array}{l}\text { Resíduo da manufatura } \\
\text { de dióxido de titânio }\end{array}$ & $\begin{array}{l}\text { Lixiviação, porosidade, absorção de } \\
\text { água, resistência à flexão }\end{array}$ & Brasil & 2015 \\
\hline [26] & $\begin{array}{l}\text { Lodo da indústria } \\
\text { papeleira }(10 \%)\end{array}$ & $\begin{array}{l}\text { Lixiviação, retração linear, absorção de } \\
\text { água, e resistência à compressão }\end{array}$ & Brasil & 2016 \\
\hline [27] & $\begin{array}{l}\text { Resíduo do } \\
\text { processamento de } \\
\text { calamita }(30 \%)\end{array}$ & $\begin{array}{l}\text { Lixiviação, resistência à flexão, } \\
\text { absorçáo de água, retração linear, } \\
\text { perda de ignição, e densidade } \\
\text { aparente }\end{array}$ & Canadá & 2016 \\
\hline
\end{tabular}

Com o aumento da temperatura de queima, e sem considerar os percentuais de resíduo incorporados, nota-se que a porosidade tende a reduzir com o aumento da temperatura de queima, o que pode ser atribuído principalmente ao processo de queima da cerâmica. Isto se deve ao fato de, em baixas temperaturas, a estrutura da cerâmica ser muito porosa e a superfície de ruptura muito rugosa, típico do estágio inicial de sinterização. Conforme há o aumento da temperatura, o volume de poros diminui e a superfície de fratura torna-se mais suave devido ao crescimento de pescoço interpartícula e a formação de uma fase líquida que, quando resfriada, transforma-se em finos filamentos vítreos (vitrificação) que tendem a preencher os poros da estrutura cerâmica. Esse preenchimento em maiores temperaturas também auxilia no aumento da resistência à flexão dos blocos cerâmicos. Com o aumento da temperatura ocorre também a redução da porosidade aberta, que culmina na redução da absorção de água e no aumento da resistência à flexão dos tijolos cerâmicos. Tal comportamento utilizando os dados de todos os artigos condiz com o evidenciado por alguns dos autores que identificaram uma relação diretamente proporcional entre a resistência mecânica e a temperatura de queima $[24,25]$.

$\mathrm{Na}$ hipótese de se retirar os dados de temperatura de queima de $850^{\circ} \mathrm{C}$ ou $1100^{\circ} \mathrm{C}$ haveria uma mudança da inclinação da linha de tendência, porém essa retirada não contribuiria para a compreensão do comportamento geral, objeto do estudo, e pelo fato desses dados corresponderem a materiais com distintas origens e constituição. Deve-se ressaltar também que os comportamentos dos materiais não são 
SERAFINI, R.; CARVALHO, J.P.B.; DE FIGUEIREDO, A.D., IMPACTOS AMBIENTAIS E TOXICOLÓGICOS DA LIXIVIAÇÃO EM TIJOLOS CERÂMICOS COM ADIÇÃO DE RESÍDUOS: UMA REVISÃO BIBLIOGRÁFICA. $3^{\circ}$ Simpósio Paranaense de Patologia das Construções (30 SPPC), artigo 3SPPC1006, pp. 60 - 71, 2018. DOI: 10.4322/2526-7248.006

necessariamente lineares com a temperatura, uma vez que a mesma afeta a formação de coalescências e cristais em temperaturas específicas, como exemplo a mulita e o espinélio, que se formam na faixa de temperatura de $1400^{\circ} \mathrm{C}$ e $950^{\circ} \mathrm{C}$, respectivamente. Na temperatura de $1100^{\circ} \mathrm{C}$ acontece a fusão de feldspato e mica potencialmente presente no material, acarretando a vitrificação que pode alterar mais fortemente o comportamento dos materiais argilosos com certo grau de contaminação. Assim, a correlação linear deve ser interpretada como a demonstração da tendência geral e não como representação comportamental dos distintos materiais.

Tabela 4: Resumo dos trabalhos avaliados

\begin{tabular}{|c|c|c|c|}
\hline Autores & Resíduo (\% em massa) & $\begin{array}{l}\text { Temperatura } \\
\text { de queima }\end{array}$ & $\begin{array}{l}\text { Norma do } \\
\text { Ensaio }\end{array}$ \\
\hline [20] & $\begin{array}{l}\text { Lodo Férrico/Waelz (5\%-35\%), areia de fundição (5\%- } \\
\text { 35\%), Argila }\end{array}$ & $850^{\circ} \mathrm{C}$ & \multirow{6}{*}{$\begin{array}{l}\text { NEN } 7345 \\
\text { em mg.m }\end{array}$} \\
\hline \multirow{5}{*}{ [21] } & Lodo físico-químico (0-60\%), Argila A & \multirow{5}{*}{$980-1050^{\circ} \mathrm{C}$} & \\
\hline & $\begin{array}{c}\text { Lodo da indústria do papel (15\%), Argila A } \\
\text { Lodo Biológico A, Resíduo Florestal, Argila A } \\
(15 \%, 5 \%, 80 \%)\end{array}$ & & \\
\hline & $\begin{array}{c}\text { Lodo Biológico B, Resíduo Florestal, Argila A } \\
(15 \%, 5 \%, 80 \%)\end{array}$ & & \\
\hline & $\begin{array}{c}\text { Lodo Biológico A, Resíduo Florestal, Argila B } \\
\qquad(15 \%, 5 \%, 80 \%)\end{array}$ & & \\
\hline & $\begin{array}{c}\text { Lodo Biológico B, Resíduo Florestal, Argila B } \\
(15 \%, 5 \%, 80 \%)\end{array}$ & & \\
\hline [22] & Lodo da indústria automotiva (1\%-40\%, Argila & $1100^{\circ} \mathrm{C}$ & \multirow{3}{*}{$\begin{array}{l}\text { TCLP } \\
\text { em mg. } \text { L }^{-1}\end{array}$} \\
\hline [23] & Cinzas de Incineração (0\%-20\%), Argila & $1100^{\circ} \mathrm{C}$ & \\
\hline [24] & Lodo Biológico (15\%), Argila & $950-1050^{\circ} \mathrm{C}$ & \\
\hline [25] & $\begin{array}{l}\text { Resíduo de dióxido de titânio(0\%-20\%), } \\
\text { Argila }\end{array}$ & $800-1100^{\circ} \mathrm{C}$ & $\begin{array}{l}\text { NBR } 10.004 \\
\text { em mg. } L^{-1}\end{array}$ \\
\hline$[26]$ & Lodo da indústria do papel, Argila (10\%, 90\%) & $750^{\circ} \mathrm{C}$ & $\begin{array}{l}\text { NBR } 10.004 \\
\text { em } \mathrm{mg}^{-1} \mathrm{~L}^{-1} \\
\end{array}$ \\
\hline \multirow{2}{*}{ [27] } & \multirow{2}{*}{$\begin{array}{l}\text { Resíduo de processamento de calamina (0\%-40\%), } \\
\text { Argila }\end{array}$} & \multirow{2}{*}{$1050^{\circ} \mathrm{C}$} & $\begin{array}{l}\text { NEN } 7375 \\
\text { em mg. } .^{-1}\end{array}$ \\
\hline & & & $\begin{array}{c}\text { TCLP } \\
\text { em mg. } L^{-1}\end{array}$ \\
\hline
\end{tabular}

Já na série de gráficos que correlacionam as propriedades com o aumento do teor de adição, nota-se que há um aumento da porosidade e, consequentemente, da absorção de água. Este comportamento, contrário ao evidenciado em cerâmicas puras, pode ser atribuído ao elevado teor de matéria orgânica presente nos resíduos que é liberada durante o processo de queima, deixando vazios na estrutura do material. Estes vazios contribuem, então, de forma direta para o aumento da porosidade e absorção de água dos tijolos com adição de resíduo, e, consequentemente, afeta às propriedades mecânicas do material. Neste quesito, os autores [23, 24, 26, 27] também evidenciaram uma relação inversamente proporcional entre a resistência mecânica e o percentual de resíduo utilizado. 
SERAFINI, R.; CARVALHO, J.P.B.; DE FIGUEIREDO, A.D., IMPACTOS AMBIENTAIS E TOXICOLÓGICOS DA LIXIVIAÇÃO EM TIJOLOS CERÂMICOS COM ADIÇÃO DE RESÍDUOS: UMA REVISÃO BIBLIOGRÁFICA. $3^{\circ}$ Simpósio Paranaense de Patologia das Construções (30 SPPC), artigo 3SPPC1006, pp. 60 - 71, 2018. DOI: 10.4322/2526-7248.006
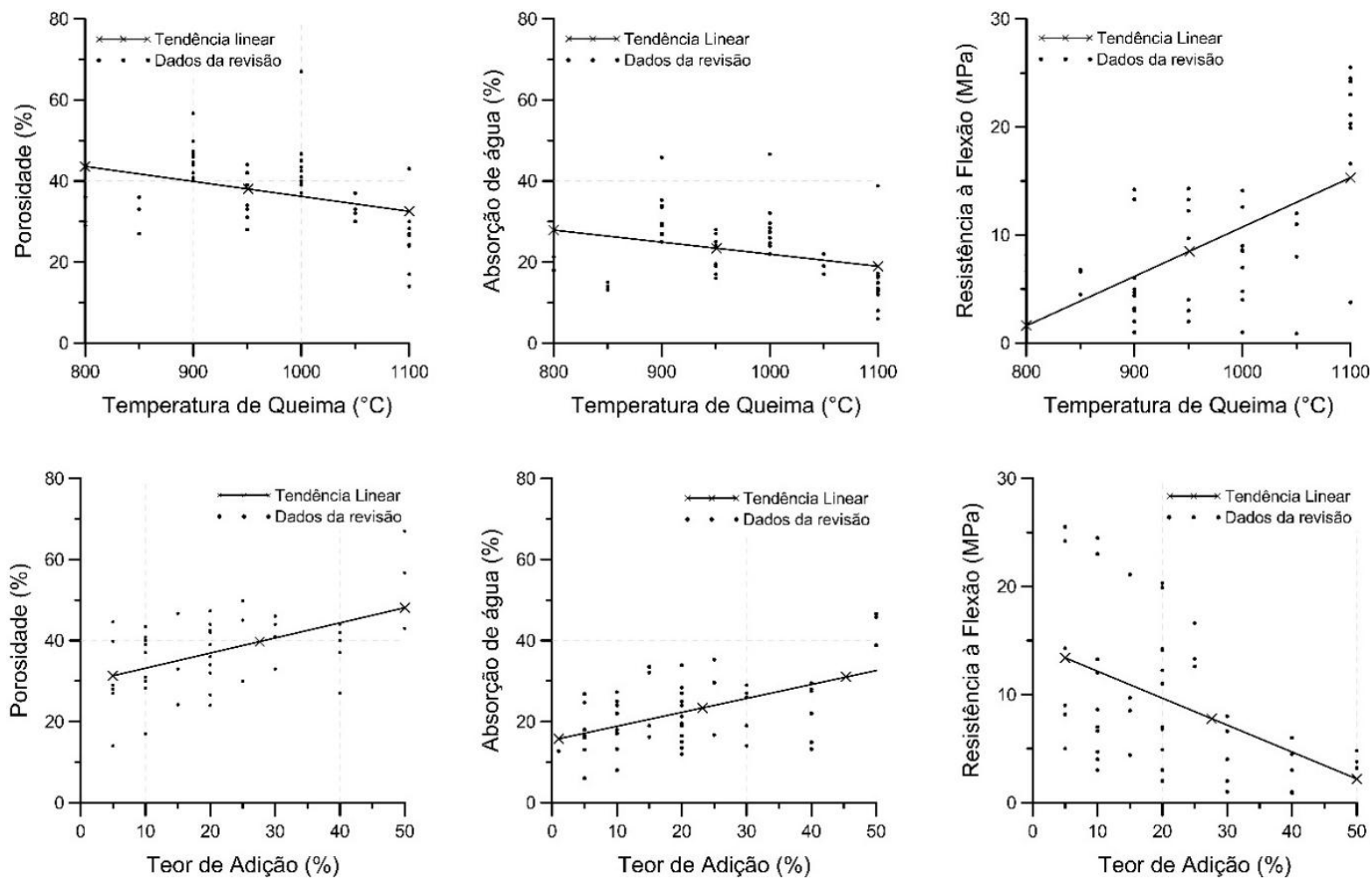

Figura 1: Propriedades em função das variáveis de temperatura de queima e teor de adição

Entre os trabalhos avaliados, foi unânime a constatação de que a incorporação de seu respectivo resíduo conseguiu manter os elementos perigosos lixiviados dentro dos limites normativos, excedendo-se apenas os tijolos com teor de $30 \%$ em peso de escória de Warlz na mistura, trabalho realizado por [20], o qual não foi capaz de satisfazer o limite de lixiviação de Molibdênio (Mo). Já no que tange os impactos da incorporação do resíduo à saúde humana, de forma específica, o único trabalho a avaliar este quesito foi desenvolvido por [21] e, de acordo com os resultados, as implicâncias sanitárias encontram-se dentro dos limites permitidos. Nota-se também que o método de ensaio mais utilizado para $\mathrm{E} / \mathrm{S}$, entre os trabalhos avaliados, é o método holandês - o que corrobora com a afirmação dos autores [9] que defendem que este é o modelo mais aceito.

Com base nos trabalhos de [20] e [21] realizou-se a análise da concentração dos elementos lixiviados Bário (Br), Cromo (Cr) e Níquel (Ni) em função da adição do teor de resíduo na massa cerâmica, ambos utilizaram o método holandês para execução do ensaio de lixiviação (ver Figura 2).

É possível notar, portanto, que há o aumento da concentração dos elementos com o aumento do teor de resíduo incorporado na massa cerâmica. Entretanto é importante salientar que, embora a linha de tendência aponte um aumento da concentração, estudos mais aprofundados e com um banco de dados mais extenso seriam ideais para confirmação da tendência de aumento. Além disso é importante salientar que esta análise não leva em consideração a concentração inicial de cada elemento presente no resíduo antes de sua incorporação, nem o tipo de resíduo, apenas valores relacionados ao teor de incorporação e a concentração dos respectivos elementos na solução lixiviada. 
SERAFINI, R.; CARVALHO, J.P.B.; DE FIGUEIREDO, A.D., IMPACTOS AMBIENTAIS E TOXICOLÓGICOS DA LIXIVIAÇÃO EM TIJOLOS CERÂMICOS COM ADIÇÃO DE RESÍDUOS: UMA REVISÃO BIBLIOGRÁFICA. $3^{\circ}$ Simpósio Paranaense de Patologia das Construções (30 SPPC), artigo 3SPPC1006, pp. 60 - 71, 2018. DOI: 10.4322/2526-7248.006
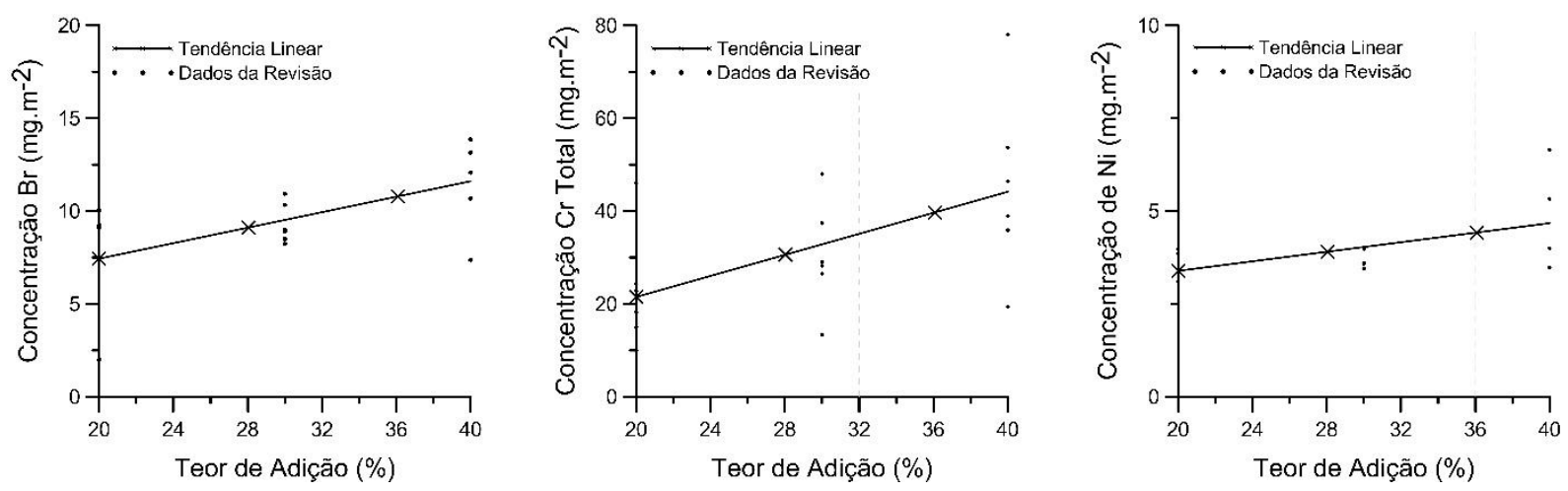

Figura 2: Concentração dos elementos $\mathrm{Br}, \mathrm{Cr}$ e Ni em função do teor de incorporação baseados em [20, 21]

\section{Conclusões}

As principais conclusões deste trabalho, baseadas nas bibliografias consultadas, foram que:

- existe a possibilidade de incorporar resíduos das mais diversas origens em tijolos cerâmicos, desde que haja o controle do percentual de adição do resíduo, temperatura de cozimento e percentual de materiais lixiviados. Para uso com função estrutural, faz-se necessário também a realização de testes de resistência mecânica adicionais, conforme regulamentação.

- entre os trabalhos que avaliaram o impacto da adição de resíduos na saúde humana, não houveram indícios de riscos toxicológicos, mesmo em avaliações rigorosas como as realizadas por [21].

- a massa cerâmica foi capaz de, na bibliografia avaliada, estabilizar os resíduos incorporados. Entretanto a adição de $30 \%$ em peso de escória de Waelz em tijolos, referente a pesquisa realizada por [20], não obteve resultados satisfatórios para a concentração lixiviada de Molibdênio.

- a absorção de água e a porosidade aumentam proporcionalmente com o aumento do teor de resíduo na massa cerâmica acarretando na diminuição da resistência à flexão. Por outro lado, a temperatura de queima dos blocos reduz a absorção de água e a porosidade, e aumentar a resistência à flexão.

- evidenciou-se a tendência de aumento da concentração dos elementos Bromo, Cromo e Níquel em função do teor de resíduo incorporado na massa cerâmica. Embora os dados sejam consistentes e apresentem coerência lógica, estudos com maiores bancos de dados devem ser realizados a fim de confirmar a tendência encontrada.

\section{Referências Bibliográficas}

[1] SERAFINI, R.; OLIVEIRA, S.A.; NUNES, M. F. O.; PAGNUSSAT, D. T. Heritage building: a pathological and performance impact analysis. In: INTERNATIONAL CONFERENCE ON STRUCTURAL REPAIR AND REHABILITATION, Porto: Faculdade de Engenharia da Universidade do Porto, 2016. 
SERAFINI, R.; CARVALHO, J.P.B.; DE FIGUEIREDO, A.D., IMPACTOS AMBIENTAIS E TOXICOLÓGICOS DA LIXIVIAÇÃO EM TIJOLOS CERÂMICOS COM ADIÇÃO DE RESÍDUOS: UMA REVISÃO BIBLIOGRÁFICA. $3^{\circ}$ Simpósio Paranaense de Patologia das Construções (30 SPPC), artigo 3SPPC1006, pp. 60 - 71, 2018. DOI: 10.4322/2526-7248.006

[2] ÂNGULO, S.; ZORDAN, S.; JOHN, V. Desenvolvimento sustentável e a reciclagem de resíduos na construção civil. Desenvolvimento Sustentável, n. 1, p. 1-13, 2001.

[3] CONNER, J.R. Chemical Fixation and Solidification of Hazardous Wastes. Van Nostrand Reinhold, Nova lorque, 1990.692 p.

[4] WILK, C. M. Solidification/Stabilization Treatment and Examples of Use at Port Facilities. ASCE Library, Houston, Texas, EUA, 2004.

[5] ASAVAPISIT, S.; NANTHAMONTRY, W.; POLPRASERT, C. Influence of condensed silica fume on the properties of cement-based solidified wastes. Cement and Concrete Research, v. 31, n. 8, p. 1147-1152, 2001.

[6] ROSA, M. A. Caracterização da incorporação da escória de aço inoxidável em materiais cerâmicos quanto a imobilização de cromo. 2001. 150 f. Dissertação (Mestrado em Engenharia) - Programa de Pós-Graduação em Engenharia de Minas, Metalúrgica e de Materiais, Universidade Federal do Rio Grande do Sul UFRGS, Porto Alegre, RS, 2001.

[7] GUZELLA, M. F. R. Desenvolvimento de processos para imobilização de resíduos de usinas nucleares utilizando betumes nacionais. 2010. 192 f. Tese (Doutorado em Engenharia) - Programa de Pós-Graduação em engenharia Química, Universidade Estadual de Campinas - UNICAMP, Campinas, SP, 2010.

[8] POON, C. S.; CHEN, Z. Q. Comparison of the characteristics of flow-through and flow-around leaching tests of solidified heavy metal wastes. Chemosphere, v. 38, n. 3, p. 663-680, 1999.

[9] JOHN, V. M.; ÂNGULO, S. C. Metodologia para desenvolvimento de reciclagem de resíduos. Coletânea Habitare, Rio de Janeiro, vol. 4, cap. 4, p. 8-71, 2003.

[10] SPENCE, R. D.; SHI, C. Stabilization and solidification of hazardous, radioactive and mixed wastes. Waste Management, v. 16, n. 7, 2005.

[11] UNITED STATES ENVIRONMENTAL PROTECTION AGENCY (U.S. EPA). Method 1311: Toxicity Characteristic Leaching Procedure (TCLP). In: Test Methods for Evaluating Solid Waste. Washington, DC, 1992.

[12] ASSOCIAÇÃO BRASILEIRA DE NORMAS TÉCNICAS (ABNT). NBR 10.005: Procedimento para obtenção de extrato lixiviado de resíduos sólidos. Rio de Janeiro, 2004.

[13] SLOOT. H. V. D; KOSSON, D. S. Leaching Tests as a Tool in Waste Management to Evaluate the Potencial for Utilization of Waste Materials. Energy Comission of The Netherlands - ENC, Petten, 33p., jun. 1995.

[14]AMERICAN NUCLEAR SOCIETY (ANS). ANS 16.1: measurement of leachability of solidified low-level radioactive wastes. Chicago, 2003.

[15] NEDERLANDS NORMALISATIE INSTITUUT (NEN). NEN 7345: determination of the release of inorganic characteristics of inorganic constituents from construction materials and stabilized waste products. Netherlands, 1995. 
SERAFINI, R.; CARVALHO, J.P.B.; DE FIGUEIREDO, A.D., IMPACTOS AMBIENTAIS E TOXICOLÓGICOS DA LIXIVIAÇÃO EM TIJOLOS CERÂMICOS COM ADIÇÃO DE RESÍDUOS: UMA REVISÃO BIBLIOGRÁFICA. $3^{\circ}$ Simpósio Paranaense de Patologia das Construções (30 SPPC), artigo 3SPPC1006, pp. 60 - 71, 2018. DOI: 10.4322/2526-7248.006

[16] AGENCE FRANÇAISE DE NORMALIZATION (AFNOR). NFX 31-210: déchets - essai de lessivage d'un déchet solide initialement massif ou généré par un procédé de solidification. Paris, 2000.

[17] BASEGIO, T. M. Imobilização do íon cromo oriundo de cinzas de incineração de serragem de couro em corpos cerâmicos vitrificados. 2004. 134 f. Tese (Doutorado em Engenharia), Programa de Pós-Graduação em Engenharia de Minas, Metalúrgica e de Materiais, Universidade Federal do Rio Grande do Sul, UFRGS, Porto Alegre, 2004.

[18] VOGEL, A. I. Química Analítica Qualitativa. 5a edição. Rio de Janeiro: LTC Livros Técnicos e Científicos, 1992.

[19]LUNKES, M. Avaliação de lixiviação de cromo em monólito de cerâmica vermelha por imersão e irrigação. 2013. 113 f. Dissertação (Mestado em Engenharia), Programa de Pós-Graduação em Engenharia Civil, Universidade do Vale do Rio dos Sinos, UNISINOS, São Leopoldo, 2013.

[20] QUIJORNA, N.; COZ, A.; ANDRES, A. CHEESEMAN, C. Recycling of Waelz slag and waste foundry sand in red clay bricks. Resources, Conservation and Recycling. n. 65, p. 1-10, 2012.

[21] CUSIDÓ, J. A.; CREMADES, L. V. Environmental effects of using clay bricks produced with sewage sludge: Leachability and toxicity studies. Waste Management, v. 32, n. 6, p. 1202-1208, 2012.

[22] UBAQUE, C. A. G.; VACA, M. C. G.; BOHÓRQUEZ, M. L. V. Encapsulamiento de lodos de plantas de tratamiento de aguas residuales de la industria automotriz en matrices de arcilla. Tecnura, v. 17, n. 38, p. 26-36, 2013.

[23] UBAQUE, C. A. G.; HÄSSIG, A.G.; BOHÓRQUEZ, M. L. V. "Ceramic bricks made from municipal solid waste incineration-derived clay and ashes: a quality study." Ingeniería e Investigación, 2013. p. 36-41.

[24] MOZO, W.; GÓMEZ, A.; CAMARGO, G. Efecto de la adición de biosólido (seco) a una pasta cerámica

sobre la resistencia mecánica de ladrillos. Ingenierías Universidad de Medellín, vol. 14, p. 61-78, 2016.

[25] RIBEIRO, D. V.; FIGUEIREDO, S. C.; MACHADO, A. T.; DIAZ, F. R. V.; SOUZA, C. A. C. Evaluation of the incorporation of waste generated from titanium dioxide manufacturing in red ceramics. Materials Research, p. 98-105, 2015.

[26] VIEIRA, C. M. F; PINHEIRO, R. M; RODRIGUEZ, R. J. S.; CANDIDO, V. S.; MONTEIRO, S. N. Clay bricks added with effluent sludge from paper industry: Technical, economical and environmental benefits. Applied Clay Science, v. 132-133, p. 753-759, 2016.

[27] TAHA, Y.; BENZAAZOUA, M.; MANSORI, M.; YVON, J.; KANARI, N.; HAKKOU, R. Manufacturing of ceramic products using calamine hydrometallurgical processing wastes. Journal of Cleaner Production. n. 127, p. 500-510, 2016. 
[28] EUROPEAN SPACE AGENCY (ESA). ESA PSS-01-702: a thermal vacuum test for the screening of space materials, 1994.

[29]EUROPEAN SPACE AGENCY (ESA). ESA PSS-01-729: the determination of off-gassing products from materials and assembled articles to be used in a manned space vehicle crew compartment, 1991.

[30] CSN EUROPEAN STANDARS (EN) EN 12457- 1: characterization of waste Leaching - Compliance test for leaching of granular waste materials and sludges - Part 1: one stage batch test at a liquid ti solid ratio of $2 \mathrm{l} / \mathrm{kg}$ for materials with high solid content and with particle size below $4 \mathrm{~mm}$ (without or with size reduction). Brussels, 2002.

[31] CSN EUROPEAN STANDARS (EN) EN 12457- 2: characterization of waste Leaching - Compliance test for leaching of granular waste materials and sludges - Part 2: one stage batch test at a liquid ti solid ratio of $10 \mathrm{l} / \mathrm{kg}$ for materials with high solid content and with particle size below $4 \mathrm{~mm}$ (without or with size reduction). Brussels, 2002.

[32] ASSOCIAÇÃO BRASILEIRA DE NORMAS TÉCNICAS (ABNT). NBR 10.006: Procedimento para obtenção de extrato solubilizado de resíduos sólidos. Rio de Janeiro, 2004.

[33] ASSOCIAÇÃO BRASILEIRA DE NORMAS TÉCNICAS (ABNT). NBR 10.004: resíduos sólidos - classificação. Rio de Janeiro, 2004.

[34] INSTITUTO COLOMBIANO DE NORMAS TÉCNICAS Y CERTIFICACIÓN (ICONTEC). NTC-4205: ingeniería civil y arquitectura. Unidades de mampostería de arcilla cocida, ladrillos y bloques cerámicos. Bogotá, D.C. 2000. 